\title{
A Socio-Cultural Perspective into the Use of Omission in the Context of Translation
}

\author{
$\mathrm{An} \mathrm{Du}^{1}$ \\ ${ }^{1}$ College of Humanities and Foreign Languages, Xi'an University of Science and Technology, Xi'an, Shaanxi, \\ China \\ Correspondence: An Du, College of Humanities and Foreign Languages, Xi'an University of Science and \\ Technology, Lintong, Xi'an 710600, Shaanxi Province, China. E-mail: duane2006@126.com
}

Received: July 27, 2015 Accepted: August 21, 2015 Online Published: September 29, 2015

doi:10.5539/ijel.v5n5p119 URL: http://dx.doi.org/10.5539/ijel.v5n5p119

\begin{abstract}
Omission, an undeniable occurrence in translational discourse, has long been approached from the linguistic perspective. This study, nevertheless, aims to elaborate the use of omission in translation from the socio-cultural perspective due to the fact that translation is more a bi-cultural activity than a bilingual one. It is, thus, demonstrated and confirmed that the use of omission, as an essential means of adjustment in translation, is fully justified provided that the socio-cultural constraints are fully taken into consideration.
\end{abstract}

Keywords: omission, translation, socio-cultural constraints, strategy

\section{Introduction}

\subsection{Research Background}

Omission, probably a universal feature of languages, has been fully analyzed and discussed in the linguistic context. Nevertheless, to date, omission has been an arguable term in the context of translation in spite of the fact that omission frequently occurs in the translational discourse. From the translational perspective, Nicholas von Wyle demanded a total concordance, a matching of word to word, asserting that even errors must be transcribed and translated as they are an integral part of the original (von Wyle, 15th century, cited in Steiner, 2001). Delisle, Lee-Jahnke, and Cormier (2004), adopting a prescriptive stance, define omission as "a translation error where the translator fails to render a necessary element of information from the source text in the target text". Clearly, though omission as a term enters the list of translation terminology, it takes a rather negative appearance. One generally-acknowledged reason for this neglect is that the use of omission is likely to violate the "faithfulness" doctrine by not telling the target audience the whole truth. Nevertheless, faithfulness does not mean verbatim transference from the source language text (SLT) into the target language text (TLT). Besides, some biased arguments prescribe that translating literally means complete compliance with the source text, and that a minor deletion out of the source text is manipulating and misleading the target audience. With regard to the currently-existing studies on the use of omission in translation, the bulk of them focus largely on the structural and syntactic omissions, with very few giving an insight out of the socio-cultural context in which the influencing factors are embedded. Accordingly, our attempt to put the use of omission under scrutiny from a socio-cultural perspective seems both necessary and worthy.

\subsection{Previous Studies on Omission in the Context of Translation}

Unlike prescriptivists' negative stance on the use of omission, the descriptivists adopt a proactive stance in the study of omission for translational purposes and their viewpoints are noteworthy for the name and nature of omission. Descriptivists tend to describe omission both as an occurrence in translational discourse and as a strategy translators can resort to if properly used. Explicitation and implicitation strategies are generally discussed together with addition and omission strategies (Vinay \& Darbelnet, 1958, cited in Baker, 2004). Besides, omission and implicitation are handled as synonyms by Englund Dimitrova, who uses such terms as "addition-explicitation" and "omission-implicitation" (Dimitrova, 1993, cited in Baker, 2004). This shows that omission is in part academically described as a practical strategy in spite of the fact that it is always discussed following addition or implicitation. As a common phenomenon in the context of translation, omission should be put under scientific scrutiny, and such an attempt is possible and necessary. 
With regard to the use and function of omission in translation practice, some scholars have their particular points of view. Baker (2000) points out explicitly that translation by omission is one of the strategies which practising professional translators can resort to in case of non-equivalence problems at and above the word level. Following Baker's point of view on the use of omission, Leonardi (2007) also accepts that omission as one of the translation strategies. At times, the translator may decide to omit some words because they are not essential to the understanding of the text. Bastin (1996, cited in Baker, 2004) defines omission, which refers to the elimination or reduction of part of the text, as one of the modes of adaptation. Dimitriu (2006) has, in a sense, analyzed and discussed omission in an integral fashion from the translational perspective, suggesting a relatively comprehensive typology of omissions in terms of the multiple purposes for using the omission strategy in translation practice.

It is worthy of note that there are still some inadequate aspects with the previous studies. First of all, the entry of omission as a term in translation dictionaries needs to be further confirmed. Just as Dimitriu puts (2006) it, many recent dictionaries of Translation Studies do not have any particular entry for the term "omission", or (at least) for some of its partial synonyms, "implicitation", "subtraction", "economy", "condensation", or "deletion". In addition, omission may occasionally be referred to in the form of its partial synonyms. In other words, under various circumstances, translation scholars may use other synonymous terms in describing the feature of omission, making translators even more confused. This, in a sense, reveals that omission may possibly take its form in other synonyms in spite of the fact that they are altogether minimized terms in translation textbooks and dictionaries.

\subsection{Synopsis of This Study}

The present study focuses on analyzing the use of omission in the translational discourse from a socio-cultural perspective. The discussion on the rationale and constraints of using omission is highly pertinent to varied contexts in which omission occurs. This study makes use of a causal model which allows us to identify various causes of using omission and the corresponding effects. Nevertheless, we should also be clear that "we can never arrive at all the causes or effects of something as complex as translation" (Williams \& Chesterman, 2004). It is for this reason that those who are involved in the discipline of Translation Studies have to do their research by continuously questioning and answering. In this study, the basic research questions are as follows.

1. Why is omission justified as an essential means of adjustment in the context of translation?

2. In what ways are the socio-cultural constraints related to the use of omission?

3. What can be implied from the socio-cultural perspective for the use of omission in translation practice?

With these basic questions in mind, we are going to address them respectively from the socio-cultural perspective. The study adopts an analytical and inductive approach, aiming at justifying the use of omission in the context of translation by describing some examples collected out of diverse and reliable sources. The objective is to substantiate the feasibility and applicability of using omission in translation practice. Besides, the conclusion to be arrived at will lend some methodological support to systematic studies on such pertinent issues as amplification, repetition and the like.

At the same time, it should be added as a footnote here that some facts need to be clarified in advance. First, admittedly, the study is more a global inquiry than an exhaustive survey of all possible socio-cultural constraints on the use of omission. Second, the object of the study is the proper use of omission by translators, excluding those cases of inappropriate or artificial use of omission. Third, the examples used in this study are not confined in text types or genres, and therefore some generalizations can be made. Last but not least, the classification of the constraints and illustrating examples might overlap, only to highlight the most distinctive feature in point.

\section{The Rationale of Using Omission in the Socio-Cultural Context}

Translation is more a bi-cultural activity than merely a bilingual one. According to Nida (2001), for truly successful translating, bi-culturalism is even more important than bilingualism, since words only have meanings in terms of the cultures in which they function. Thus cultural approach to translation, known as cultural translation, regards "translation as a process which occurs between cultures rather than simply between languages" (Shuttleworth \& Cowie, 2004). Given the socio-cultural context in a broader sense, we want to present two points here by modifying the relevant claims. First of all, cultural translation may not, in a strict sense, render a linguistically faithful TLT, but it helps to promote better accessibility and acceptability in the target culture. Besides, cultural translation involves not only additions, but it also incorporates some other strategies including omission.

Figure 1 shows omission as a strategy is justified in the process of cultural translation. For convenience's sake, 
C-A (culture A) and C-B (culture B) represent two different cultures, like Chinese and English cultures. SAC represents shared aspects between cultures which incorporate ideology, beliefs, values, and so forth. Furthermore, $\mathrm{SAC}$, in a sense, accounts for the accessibility and possibility of translating between cultures given that "translation is always more or less possible because of the universal and the culturally overlapping constituents of language" (Newmark, 2006). Then, the question arises with regard to the independent areas that are culture-specific. Understandably, cultural differences and conflicts exist widely in terms of the culture-specific information. How should we address the culture-specific information in the translation process? To avoid cultural shock in the target readership through a stroke of devastating literal translation, a translator's job, in Newmark's point of view, may be to smash culture (ibid). In this sense, this, of course, necessitates proper adjustment means, including omission. Moreover, for the time being, cultural acceptability also advances with time. What was unacceptable in the past is gradually attuned to the current cultural context. Through communication, some elements of culture A enter culture B and become part of culture B, thus bring about cultural diffusion, which has been shaped gradually and unceasingly (Dai \& He, 2002).

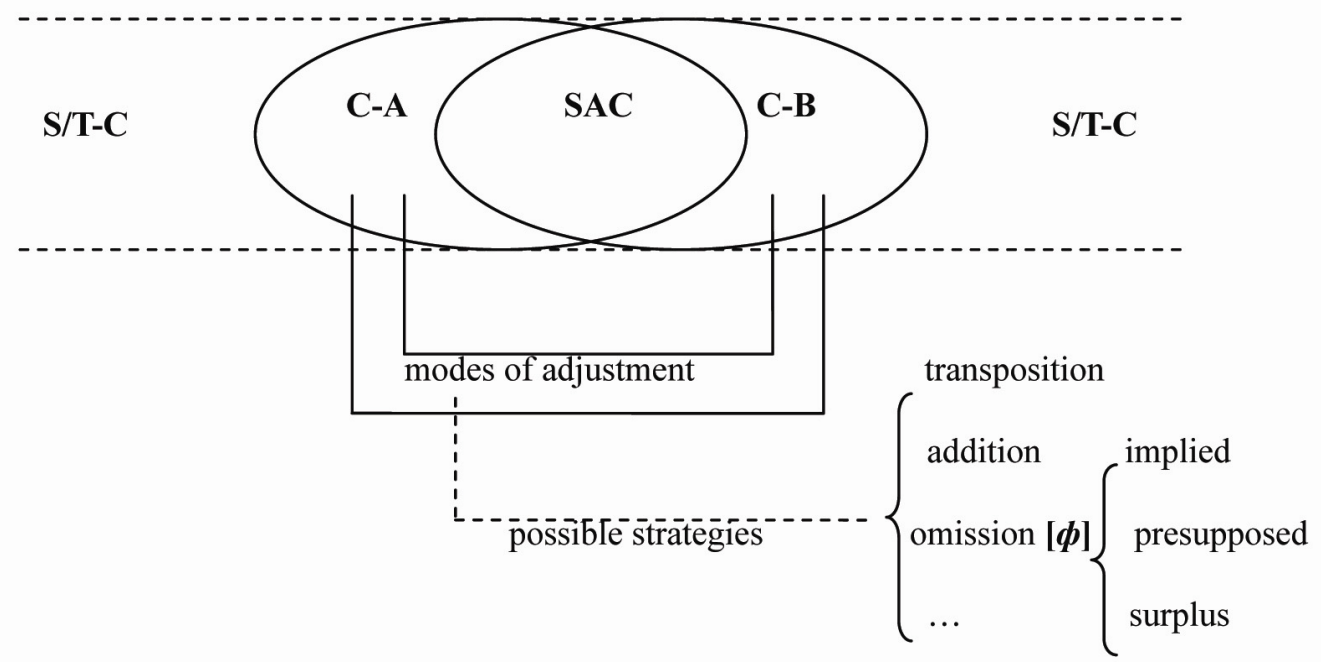

Figure 1. Omission as a strategy in the process of cultural translation

Note. C-A: culture A; C-B: culture B; SAC: shared aspects between cultures; S/T-C: spatial/temporal continuum; $[\boldsymbol{d}]$ : omission

Accordingly, omission in the socio-cultural context can be roughly classified into three types - implied, presupposed and surplus. The criterion for such a classification is in terms of the features of the omitted parts. The first two types refer to the situation in which the omitted parts can be retrieved from the contexts. The last type refers to omission of surplus information without the distortion of meanings for the TLT audiences.

\section{Socio-Cultural Constraints on the Use of Omission}

\subsection{Ideological Differences}

Translation does not take place in vacuum since it is bound to be under control of a certain society and dominant ideology within it (Hu \& Yu, 2011). Translation strategies, noticeably, tend to be ideologically motivated. Just as Fawcett points out that if, on the one hand, ideology is indeed implicated in every aspect of our human situation, then translation becomes fraught with potential accusations of imperialism every step of the way (Fawcett, 2004). Ideology has its influences on the translator's work in every respect. That is, in the shaping of a translation, ideology is an omnipresent force. As Lefevere puts it, translations are made under a number of constraints of which language is arguably the least important (Lefevere, 2004). Ideology being a broad notion, here it is, in a narrower sense, addressed from political considerations. Given different political systems between Chinese and mainstream English societies, the use of omission as an important strategy is frequently seen in the context of translation, particularly when the attempts to render it literally run the risk of provoking unnecessary confrontation and antipathy among the target audiences.

Example (Note 1):

SLT (Chinese): 学校、家庭和社会要在各级党委、政府的领导下, 互相沟通, 积极配合, 勇于开拓, 共同 开创素质教育工作的新局面。 
TLT (English): We hope that schools, families and the public will communicate and cooperate with one another, be courageous in breaking new ground, and work together to bring about a new situation in character education under rational $[\boldsymbol{\phi}]$ government guidance.

As is known to all, there are differences between China and the major English nations regarding the political systems. As for this example, the Chinese SLT audiences know well the political context in which “各级党委” refers to the committees of the Communist Party at all levels as the leading organs in the Chinese political systems. In contrast, the English target audiences primarily live in the electoral political culture characteristic of ruling in turn between two or more parties. Therefore, misunderstandings and even biased perceptions may occur among the target audiences, provided that they know little about the political context reflected in the SLT culture. Presumably, in order to avoid the possible ideological confrontation, the translator intentionally omits “各级党 委”. Understandably, this may lead to the impression that the information is lost in the English TLT. Two points are stated here to account for the omission. On the one hand, in the Chinese SLT, “在各级党委、政府的领导下” actually implies that the governments which are led by the Party committees at all levels exercise the administrative leadership in the educational management. On the other hand, the intended TLT audiences primarily involve those who are interested in China's educational reform and development. Thus, they are supposed to have some preparatory knowledge of the political differences between the two cultures. Presumably, they can, if intentionally, understand the political context in the Chinese SLT. Accordingly, the omission plays the positive part in avoiding unnecessary ideological confrontation. Omission may become a subtle, indirect manner of promoting everything that is in keeping with the ideology in the service of which a translator works and deleting everything that runs counter to it (Dimitriu, 2006).

Nevertheless, one should not gain the misconception that the politically sensitive expressions can, in any case, be omitted to satisfy the target audiences. As a matter of fact, it hinges on the situations. The following example is given to illustrate our point.

Example (Note 2):

SLT (Chinese): 各民主党派充分发挥协调关系、化解矛盾的重要作用, 努力做好反映社情民意工作, 为中 国共产党各级党委和各级政府的科学决策、民主决策服务。

TLT (English): All the democratic parties make full use of their important role as coordinators and problem solvers to do a good job of reporting social conditions and public opinions to the higher authorities and to help the CPC committees and governments at all levels in scientific and democratic decision-making.

The SLT is quoted from China's Political Party System published by the Information Office of the State Council of the People's Republic of China. That is, it is an official document released by the Chinese government. It, thus, goes without a shadow of doubt that the SLT is formal, serious and authoritative. Accordingly, the English TLT is supposed to accurately convey the information, taking little account of the extra-linguistic factors, like ideological confrontation and readers' response in the target cultural context. In other words, under such circumstances, the sake of accuracy, in a sense, overrides that of reception in the target culture. The same SLT expression “各级党委” is rendered totally differently in the two TLT versions. In the former example omission is adopted, whilst in the latter it is not. Why is there such a difference? There are, of course, various reasons for the difference. The function of the SLT and the communicative intention of TLT are the major ones to account for the difference. Besides, the two examples illustrate the necessity of taking the communicative situations into consideration when confronting ideological differences. In other words, to make proper adjustment in confronting ideological differences, a flexible and dynamic view in using omission is appropriate and justifiable.

\subsection{Cultural Bumps}

"Cultural bumps" refer to certain unique culture-specific terms or expressions which may appear as a conundrum for translators. They are typically representative of a certain culture or a cultural community. Some of them can be rendered by recourse to adding information or footnotes in the margin, or compensation in some possible ways. However, some are untranslatable in practice in that illustration of any sort will be redundant and cause even more confusions. Under such circumstances, the translator can resort to the omission strategy by leaving out the terms or expressions overloaded with cultural information.

Example (Note 3):

SLT (Chinese): 二人看时, 一张供桌, 香炉、烛台, 供着个金字牌位。上写道: “赐进士出身, 广东提学 御史, 今升国子监司业, 周大老爷长生禄位。”左边一行小字, 写着: “公讳进, 字萝轩, 邑人”。

TLT (English): There were incense-burners and candlesticks on the table, and above it a memorial tablet on which was written in letters of gold an account of the vice-president's career $[\boldsymbol{\phi}]$. 
The translated version produced by Yang Xianyi and Gladys Yang is generally accepted as the closest version so far. On close observation, we will find that the omission strategy is constantly resorted to by the translators especially in addressing culture-specific terms like “字”“号”,“称谓”,“官职”. Such terms do not have equivalents in English, and thus, they are mostly omitted by the translators resolutely. The translators omit the culture-specific terms primarily for the consideration of TLT readers' response. The translators meticulously compensate for the omission through generalizing the relevant meanings to fill the void. This feature can be also seen as a process of simplification, which distinguishes the proper omission - an advisable strategy from random deletion - an irresponsible mistranslation.

Besides, there is another major type of omission of cultural bumps. It has the feature that the omitted parts have been presupposed in the previous part. Tentatively, we can also assume that omission of this type is zero-anaphoric reference in the co-text context. In other words, the omitted cultural bumps have been intentionally illustrated somewhere previously in the context. Here is an example in point.

Example (Note 4):

\section{SLT (Chinese)：母亦爱其柔和，即脱金约指缔姻焉；此乾隆乙未七月十六日也。}

TLT (English): My mother also liked her being so gentle, and gave her her gold ring as a token for the betrothal. This was $[\boldsymbol{\phi}]$ on the sixteenth of the seventeenth moon in the year 1775 .

The translated version produced by Lin Yutang is widely appreciated both among the target audiences and translation critics for its authentic language and faithful style. As for the use of omission in the example, we can find that the translator did not render the literal meaning “乾隆乙未”in the English TLT. Why did he omit the underlined words? There are possibly two major reasons. First, the omitted words, as culture-specific terms in the SLT context, play the functioning role of recording the date. In other words, in the SLT they do not have symbolic implications as cultural terms, and thus are surplus information in the TLT context. And the translator reproduces the SLT function through recourse to modern way of designating the exact year "1775". Second, the culture-specific term “乾隆” has been presupposed in the co-text. In the beginning part of the story there is a line “余生乾隆癸未冬” providing the essential background information for the intended readership, which is literally rendered as "I was born in 1763, under the reign of Ch'ienlung". Thus, the background information given in preceding text justifies the omission of this term in the following parts of the TLT.

\subsection{Cultural Taboos}

Cultural taboos exist and some of them are strong enough to be shared by several cultures. In other words, some taboos may also be tolerated with audiences of other cultures. However, it is easily understood that taboos may also be culture-specific and thus appear as an obstacle in translation. Therefore, taboos impose a strong ban on doing certain activities or discussing certain topics so they are likely to be omitted from social behavior or writing (Dimitriu, 2006).

Example (Note 5):

SLT (English): "But you are beautiful" she said. "So pure and fine! Come!" She held her arms out ... He was ashamed to turn to her, because of his aroused nakedness.

TLT (Chinese): “你真美！”她说, “如此纯洁, 如此美妙！来吧！”她张开了双臂。

$$
\text { 他不好意思地转过身去....... [ } \boldsymbol{\phi}]
$$

Eroticism has long been for a source of contention in the literary world, which is certainly true of D. H. Lawrence's Lady Chatterley's Lover. What pertains to our present discussion is a well-accepted Chinese version by Zhao Susu, in which omission is occasionally resorted to especially regarding eroticism. The translator meticulously omits them partly for the sensitiveness of the relevant content. Some may, understandably, argue for the omission for fear of information loss and aesthetic ineffectiveness. In spite of the metaphorical and symbolic meanings implied in the SLT, the omissions in the examples seemingly result in information loss, yet notably, the translator intentionally use the ellipses "......" to indicate the omitted parts in the text, and predictably the use of the punctuation functions to provide sufficient space of imagination for the target audiences. Thus, to a very real extent, such omission helps to achieve the contextual effect rather than diminish it. In other words, the intended audiences will, if carefully, predict or retrieve out of their experiential knowledge what has been omitted in the specific contexts.

It needs to be noted here that the problem of social acceptability of eroticism in literary works exists both in Chinese and English cultures, but the degree of tolerance towards it differs. Xie (1999) acknowledges that sex is the most sensitive area in the Chinese cultural context. In average literary works, the overt depictions of sexual 
organs are seldom seen, and it can, thus, be regarded as a taboo subject. Nevertheless, cultural taboos are not just confined in the subject of sex, which may take a variety of forms. Sex, religion, and defecation are taboo subjects in many societies, but not necessarily to the same degree within similar situations. In some translation contexts, being polite can be far more important than being accurate. A translator may decide to omit or replace whole stretches of text which violate the reader's expectations of how a taboo subject should be handled - if at all - in order to avoid giving offense (Baker, 2000).

\section{Conclusion}

The use of omission in translation is not a mere matter of personal preference, but rather a justifiable means of adjustment with a full consideration of the pertinent socio-cultural constraints. In confronting such constraints as ideological differences, cultural bumps and cultural taboos, translators are supposed to play the role of being a mediator between cultures, and for effect, they may frequently have recourse to a set of means of adjustment with omission being one of them. Last but not least, omission should by no means be used randomly and excessively, but instead, it ought to be applied flexibly and dynamically in actual situations of practice for the ultimate purposes of acceptability and diffusion in the target culture.

\section{References}

Baker, M. (2000). In Other Words: A Coursebook on Translation. Beijing: Foreign Language Teaching and Research Press.

Baker, M. (Ed.). (2004). Routledge Enclopedia of Translation Studies. Shanghai: Shanghai Foreign Language Education Press.

Dai, W., \& He, Z. (Eds.). (2002). A New Concise Course on Linguistics for Students of English. Shanghai: Shanghai Foreign Language Education Press.

Delisle, J., Lee-Jahnke, H., \& Cormier, M. (2004). Translation Terminology. Beijing: Foreign Language Teaching and Research Press.

Dimitriu, R. (2006). Omission in translation. In X. Luo (Ed.), Perspectives: Studies in Translatology (vol. III, pp. 171-183). Beijing: Tsinghua University Press.

Fawcett, P. (2004). Ideology and Translation. In M. Baker (Ed.), Routledge Enclopedia of Translation Studies (p. 107). Shanghai: Shanghai Foreign Language Education Press.

Hu, Z., \& Yu, F. (2011). Ideology and Poetics in the English Translation of Ah Q Zheng Zhuan. Academics, 6, 253.

Lefevere, A. (2004). Translation, Rewriting and the Manipulation of Literary Fame. London \& New York: Routledge.

Leonardi, V. (2007). Gender and Ideology in Translation: Do Wemen and Men Translate Differently? - A Contrastive Analysis from Italian into English. Bern: Peter Lang AG, International Academic Publishers.

Newmark, P. (2006). About Translation. Beijing: Foreign Language Teaching and Research Press.

Nida, E. (2001). Language and Culture: Contexts in Translating. Shanghai: Shanghai Foreign Language Education Press.

Shuttleworth, M., \& Cowie, M. (2004). Dictionary of Translation Studies. Shanghai: Shanghai Foreign Language Education Press.

Steiner, G. (2001). After Babel: Aspects of Language and Translation. Shanghai: Shanghai Foreign Language Education Press.

Williams, J., \& Chesterman, A. (2004). The Map: A Beginner's Guide to Doing Research in Translation Studies. Shanghai: Shanghai Foreign Language Education Press.

Xie, T. (1999). Medio-translatology. Shanghai: Shanghai Foreign Language Education Press.

\section{Notes}

Note 1. Source of the example: 李岗清. (2003). 《李岗清教育访谈录》(中文版). 北京: 人民教育出版社; Li Lanqing. (2004). Education for 1.3 Billion (English version). Beijing: Foreign Language Teaching and Research Press.

Note 2. Source of the example: 中华人民共和国国务院新闻办公室. (2007). 《中国的政党制度》; China's 
Political Party System (English version). (2007). Beijing Review. No.47. Nov. 22.

Note 3. Source of the example: (清)吴敬梓. 《儒林外史》; 杨宪益、戴乃迭 译.Trs. Yang Xianyi \& Gladys Yang. (2004). The Scholars (English version). Beijing: Foreign Languages Press.

Note 4. Source of the example: (清)沈复. 《浮生六记》; 林语堂 译. Tr. Lin Yutang. Six Chapters of a Floating Life (English version). (1999). Beijing: Foreign Language Teaching and Research Press.

Note 5. Source of the example: Lawrence, D. H. (1997). Lady Chatterley's Lover. London: Penguin Books; 赵 苏苏 译. Tr. Zhao Susu. (2004). 《查特莱夫人的情人》(Chinese version). 北京: 人民文学出版社.

\section{Copyrights}

Copyright for this article is retained by the author(s), with first publication rights granted to the journal.

This is an open-access article distributed under the terms and conditions of the Creative Commons Attribution license (http://creativecommons.org/licenses/by/3.0/). 